\title{
CORPO E IDENTIDADE: UM OLHAR SOBRE MULHERES PRATICANTES DE BODYBUILDING
}

\author{
BODY AND IDENTITY: ON FEMALE BODYBUILDERS
}

CUERPO E IDENTIDAD: UNA MIRADA SOBRE MUJERES PRACTICANTES DE FISICULTURISMO

\section{Amanda Mello Andrade de Araújo*, Alexandre Fernandez Vaz ${ }^{\star *}$, Jaison José Bassani**}

Palavras chave:

Aparência corporal.

Treinamento

de resistência.

Mulheres.

Regime alimentar.
Resumo: 0 estudo tratou de investigar a relação entre a modificação corporal e 0 processo de construção identitária em mulheres praticantes de bodybuilding na cidade de Brasília/DF. Para isso, foram entrevistadas sete mulheres que aderem ao treinamento intenso de musculação e dieta alimentar restrita, sendo seis delas atletas e apenas uma não atleta. Os resultados, apresentados e discutidos sob a forma de eixos de análise, revelam: 1) modos ascéticos particulares como as entrevistadas operam com restrições (alimentares e de treinamentos musculares) a que estão submetidas em busca do corpo almejado; 2) que a forma de operar e dar sentido ao corpo tanto para as atletas quanto para a veterana indica construção de identidades distintas.

Keywords:

Physical appearance

Body.

Resistence training. Women.

Diet.

Palabras clave: Apariencia corporal. Entrenamiento de resistencia.

Mujeres.

Dieta. process of identity construction in female bodybuilders in Brasilia, DF. Seven women - six athletes and one non-athlete - who practice intense bodybuilding and restricted diet were interviewed. The results are presented and discussed as interconnected categories and reveal that 1 ) they have particular ascetic ways to deal with (dietary and muscle training) restrictions to reach the desired body and 2) the ways of operating and ascribing meaning to their own bodies are very important to build the identities of both the athletes and the non-athlete.

Resumen: El estudio buscó investigar la relación entre la modificación del cuerpo y el proceso de construcción identitaria en mujeres practicantes de fisiculturismo en Brasilia/ DF. Para ello, fueron entrevistadas siete mujeres que adhieren al entrenamiento intenso de la musculatura y a una dieta alimentaria restringida, seis de ellas atletas y solo una no atleta. Los resultados, presentados y discutidos bajo la forma de ejes de análisis, revelan: 1) formas ascéticas particulares en que las entrevistadas operan con restricciones (alimentarias y de entrenamiento muscular) a que están sometidas para obtener el cuerpo deseado, 2) que la forma de operar y dar sentido al cuerpo, tanto para las atletas como para la veterana no atleta, indica la construcción de identidades distintas.
Abstract: This study looked into the relationship between body modification and the
*Colégio Pedro Il. Rio de Janeiro, RJ, Brasil.

E-mail: salutamanda@ hotmail.com

**Universidade Federal de Santa Catarina. Florianópolis, SC, Brasil. E-mail: alexfvaz@uol.com.br; jaisonbassani@uol.com.br

Recebido em: 02-09-2017 Aprovado em: 29-08-2018

DOI: https://doi.org/10.22456/1982-8918.76213 (c) (1) 은 Licence 


\section{INTRODUÇÃOO}

As preocupações com o corpo, embora também estivessem presentes em outras épocas, ganharam tamanha centralidade no contemporâneo de modo que não seria exagero dizer que a ele foi atribuída importância semelhante a que outrora pertencia à alma (SANT'ANNA, 2000). Essa afirmação pode ser interpretada tanto em relação ao interesse das mais diferentes áreas do conhecimento pelo somático quanto pela dimensão que os cuidados com o corpo e as diversas possibilidades de modificá-lo adquiriu na sociedade atual. Conforme coloca Costa (2004, p.192), o cientificismo atribui ao corpo um valor em si mesmo, de modo que "ele deixa de ser um meio de agir sobre o mundo ou de enobrecer sentimentos para voltar-se para as finalidades de sua própria conservação e produção". Na esteira dessa cultura, vemos cada vez mais a disseminação de prescrições sobre como gerenciá-lo, além da ampliação mercadológica de produtos e espaços destinados ao culto do corpo. Entre esses espaços, incluem-se as academias de ginástica e musculação, bastante presentes nos centros urbanos.

Esses ambientes de educação do corpo, devido à dimensão que ganharam, instituem e reforçam um modelo específico de construção identitária de homens e mulheres (HANSEN; VAZ, 2004). Embora integrados nesse contexto estejam os praticantes de bodybuilding', eles se destacam dentro da lógica das academias. 0 bodybuilding é uma prática de modificação corporal que visa à hipertrofia muscular obtida por meio de intenso treinamento e estrita dieta. É comum que praticantes dessa modalidade, para alcançarem a forma corporal almejada, rompam as barreiras daquilo que, histórica e culturalmente, consideramos como "saudável" e "normal" nos termos dos modelos corporais socialmente aceitos. Longe de se firmar exclusivamente como domínio masculino, essa prática vem crescendo também entre as mulheres. Sabino e Luz (2014), que pesquisaram o ambiente das academias de musculação do Rio de Janeiro há alguns anos, ${ }^{2}$ afirmam que em alguns desses espaços o número de mulheres praticando lutas, fitness e bodybuilding supera 0 de homens.

As modificações corporais, em geral, e o bodybuilding, em específico, além de serem lidos como expressão de uma cultura somática contemporânea, parecem se constituir também como parte importante dos investimentos em uma subjetividade distinta daquela que vigorou no auge da modernidade e que tinha forte caráter internalista (COSTA, 2004; ORTEGA, 2012). Se antes a identidade do sujeito estabelecia uma relação com as instâncias do trabalho, da política, da ética e da religião, por exemplo, e na qual a dimensão fisicalista se colocava como um meio para uma subjetividade definida publicamente, atualmente a ênfase na gerência do corpo e toda a teia de intervenções que sobre ele incide parecem admitir um modelo de construção de um "sujeito corporificado" (ORTEGA, 2012, p. 42).

Para o autor citado abaixo, o interesse em aproximar-se de um modelo específico de corpo, cada vez mais comum em nosso tempo, não é fortuito. Seria resultado de uma cultura na qual as formas de se relacionar no interior das práticas sociais passam a ter o corpo como elemento central:

$\mathrm{Na}$ biossociabilidade e na cultura do ascetismo contemporâneo, a medicina se encontra novamente implicada em definir o estatuto filosófico do homem. As formas de biossociabilidade e bioascese são uma peça fundamental no

1 Embora possa ser comumente traduzido como fisiculturismo, optaremos por manter o termo bodybuilding com o intuito de extrair o sentido literal da tradução da palavra: construção do corpo. 
processo de desmontagem da cultura íntima e de somatização e exteriorização da subjetividade. Com as bioasceses, a distinção entre corpo e o self perdeu sua relevância. Mediante as atividades de fitness o psiquismo é externado, os indivíduos são somatizados (ORTEGA, 2003, p. 62).

Assim, ao nos voltarmos para mulheres praticantes de bodybuilding, interrogamo-nos sobre os processos que estão em jogo quando elas, ao aparentemente abdicarem de elementos de uma feminilidade normalizada, buscariam, talvez, outra subjetividade que se evidenciaria igualmente na aparência, embora não mais naqueles atributos hegemonicamente considerados como tipicamente femininos ${ }^{3}$. Qual então seria a relação entre práticas de modificação corporal e processos de construção identitária em mulheres praticantes de bodybuilding? A tentativa de responder a esta pergunta conduziu-nos ao objetivo de investigar a relação entre a prática de modificação corporal e processos de construção de identidades em mulheres praticantes de bodybuilding.

Embora as discussões que prevalecem em torno da temática deste estudo se concentrem nas questões acerca do lugar da feminilidade no processo de construção e manutenção do corpo da bodybuilder, é preciso lembrar que também esta dimensão de investigação não se dá distante de um contexto em que novas formas de sociabilidade, preceitos éticos e identidades se esquematizam tendo o corpo como lócus privilegiado. Compreendemos, nesse sentido, que frequentadores de academias de musculação, especialmente mulheres praticantes de bodybuilding, podem fornecer indicativos importantes de como se reorganizam os elementos supracitados, uma vez que parecem condensar, principalmente, as vicissitudes de um processo mais amplo, presente de diferentes maneiras e intensidades em diversos tempos e espaços sociais no contemporâneo. Dito de outra forma, neste momento nos concentramos em observar em que medida esse engajamento na construção do corpo faz parte ou não de um fenômeno mais amplo, tal como descrito por Ortega (2012), sobre a externalização da subjetividade.

$\mathrm{Na}$ sequência, apresentaremos algumas considerações sobre o contexto geral da pesquisa, com especial atenção às entrevistadas. Para fins de organização e apresentação dos resultados, elegemos dois eixos de análise que se concentram: 1) nas severas demandas e restrições (alimentares e de treinamentos musculares) a que estão submetidas em busca do corpo almejado; e 2) nos distanciamentos e aproximações entre competidoras e veterana nos aspectos identitários.

\section{ASPECTOS METODOLÓGICOS}

As perguntas que movem a pesquisa condicionaram nosso percurso a centrar-se na escuta das narrativas dessas personagens. Um aspecto metodológico importante que precisou ser contornado foi a não familiaridade dos pesquisadores com o campo envolvido. Por esse motivo, priorizamos, em um primeiro momento, o contato com as participantes intermediado por terceiros (amigos e conhecidos praticantes de musculação que pudessem nos apresentar para potenciais sujeitos da pesquisa). Essa opção de aproximação, acreditávamos, minimizaria certa desconfiança que as participantes poderiam ter em relação à pesquisa. Afinal, nossos próprios corpos denunciavam nossa condição de outsiders.

3 Embora a questão sobre a feminilidade tenha sido fundamental para a construção da problemática desta pesquisa, optamos por desenvolvêla em outra ocasião. Sobre o tema consultar Araújo (2013). 
Realizamos sete entrevistas semiestruturadas com mulheres entre 21 e 44 anos que praticavam bodybuilding há pelo menos dois anos na cidade de Brasília, Distrito Federal. ${ }^{4}$ Para tanto, foi elaborado um roteiro orientador, contendo questões sobre dados biográficos, tempo de prática de musculação e estrutura de treinamento, cuidados com alimentação, saúde e embelezamento, avaliações sobre a prática do bodybuilding, representações sobre o corpo e o feminino, entre outros aspectos.

Todas as entrevistas, concedidas de forma voluntária e após assinatura do Termo de Consentimento Livre e Esclarecido ${ }^{5}$, foram gravadas (áudio) e posteriormente transcritas para análise. Observamos também o V Campeonato Brasiliense de Fisiculturismo (05/08/2012), do qual as entrevistadas participaram, e consultamos a rede social Facebook, em que a maioria das entrevistadas mantinha perfil ativo.

No momento da realização da investigação, seis delas moravam no Distrito Federal e uma, que estava na cidade para participar como atleta homenageada no citado campeonato, era do Mato Grosso do Sul. Das participantes habitantes do DF, três viviam em cidades do entorno de Brasília - Valparaíso, Vicente Pires e Guará - e as outras três no Plano Piloto. Todas cursavam ou haviam cursado nível superior. Apenas três áreas de atuação/formação profissional apareceram em seus depoimentos: Engenharia (1), Direito (3) e Educação Física (3). Apensas uma era casada. Duas tinham filhos, sendo que uma morava com a mãe e não tinha renda própria. Outras três tinham emprego fixo e provinham seu próprio sustento. Apenas uma das entrevistadas não havia ou não estava em vias de participar de competições de fisiculturismo.

Inspirados em Sabino (2004), diferenciamos competidoras (fisiculturistas) de não competidoras (veteranas). Para preservar a identidade das participantes, os nomes aqui utilizados são fictícios. Os eixos de análises apresentados a seguir foram organizados a partir de elementos discursivos representativos, sobretudo aqueles que expressassem, para as participantes, representações a respeito de seus corpos, do treinamento e de suas identidades, e de observações dos respectivos perfis em redes sociais.

\section{TREINO E DIETEICA: NOVAS ASCESES}

Se podemos falar a respeito de um etos forjado dentro das academias de ginástica e musculação que tem forte imbricação com todo um conjunto de técnicas que promovem certa incorporação da performance (HANSEN; VAZ, 2004), quando se trata das praticantes de bodybuilding, isso parece se manifestar de maneira mais evidente. $O$ treinamento de hipertrofia ganha não só mais intensidade, como também em frequência e especificidade. As sessões duram cerca de uma hora e são realizadas de seis a sete dias por semana para a maioria das entrevistadas 6 . Em cada treino, grupos musculares distintos são trabalhados. A estratégia mais comum para "queima" de gordura corporal são os exercícios cardiorrespiratórios, que levam em torno de quarenta minutos por sessão.

40 número de sete entrevistas foi definido em função do ponto de saturação das respostas, considerando as questões orientadoras e os objetivos da investigação. Adotamos os seguintes critérios gerais de inclusão: mulheres maiores de 18 anos de idade; praticantes regulares ou competidoras de bodybuilding há pelo menos um ano; disponibilidade para participar voluntariamente da pesquisa.

5 No TCLE foram explicados os objetivos da investigação, informações sobre procedimentos éticos adotados e condições para participação da pesquisa. 
Embora a fragmentação do trabalho muscular seja uma característica central da prática de musculação para qualquer adepto, no caso das praticantes de bodybuilding ela apresenta certas peculiaridades. Se um princípio geral do treinamento esportivo é a especificidade, no caso dessas mulheres parece ser necessário antes atender às demandas "genéticas":

É porque é genética. Tem alguma coisa que tem a ver com genética. Assim, você muda. Você pode alcançar o limite, mas só que eu acho que chega um ponto e você fala 'qual a genética do meu corpo?', aí você fala 'é essa!'. Eu posso querer ter a bunda gigantesca, mas assim... você não vai ter! Acho que você tem que seguir o padrão do corpo que você tem e só ir melhorando (Fernanda, 21 anos) ${ }^{7}$.

A busca da perfeita harmonia e simetria da musculatura faz com que o treinamento priorize excessivamente algumas partes que "a genética não favoreceu", em detrimento de outras em que o ganho muscular parece ser "mais fácil". Uma das entrevistadas relatou que não realizava treino de coxa havia um ano e que mesmo assim seu quadríceps apresentava dimensões excessivas, que não eram de seu agrado. Tudo indica que a necessidade de "aprimoramento" da musculatura é prevalecente, além de parecer se configurar como um estado permanente entre as depoentes. Um estado que só parece ser justificado quando se admite o próprio corpo como um objeto passível de modulação e modificação (VAZ, 1999), mas que pode encontrar na carga genética (de fato ou imaginariamente) uma barreira ou 0 limite para o seu aperfeiçoamento. A genética aparece, nesse caso, como o inacessível, talvez a mais genuína expressão da nossa natureza, sobre a qual, sabemos, há muito o ser humano tenta triunfar 8 .

No caso das competidoras, a harmonia e a simetria musculares adquirem um sentido que não leva em consideração estritamente a divisão sexual do trabalho muscular (SABINO, 2000), segundo a qual homens priorizariam o treinamento dos membros superiores enquanto as mulheres se preocupariam quase que exclusivamente com glúteos e pernas. Respeitando as diferenças entre os distintos níveis e categorias, no naipe feminino da modalidade de bodybuilding a atenção deve ser dada, até certo ponto, aos grupos musculares tradicionalmente associados aos homens. Joana ${ }^{9}$, por exemplo, dizia dar destaque aos deltoides. Um "porte de ombros largos" é sempre enaltecido nas competições, segundo ela.

O objetivo em ter o corpo treinado para as competições, mas também para outras finalidades sociais, faz com que, entre as mulheres pesquisadas, não só o momento da "malhação" seja destinado ao alcance desse fim. A construção do corpo toma centralidade tal que a organização da vida das praticantes precisa estar em consonância com isso. A dieta, por exemplo, é parte relevante de um modo de ser de uma bodybuilder. Na esteira do que escreve Sabino (2004), os planos alimentares são construídos sob influência dos discursos médico-científicos, fazendo com que a solicitação de especialistas se torne imprescindível. As orientações desses conselheiros, como mostrado no relato abaixo, tomam ares de verdade quase inquestionáveis:

Eu falo, não, vou deixar isso [alimentação] com quem entende. Aí eu só faço. Se a pessoa me mandar ficar de cabeça para baixo, eu vou ficar. Se a nutricionista mandar: 'oh esse mês você vai passar fome', eu vou passar (Fernanda, 21 anos).

\footnotetext{
7 Fernanda, 21 anos, então estudante de Direito. Embora praticante de musculação havia oito anos, decidira aderir ao bodybuilding há cerca de um ano e meio antes. Fernanda era a única não atleta neste estudo.

8 Em Vaz (1999, p. 92) lemos: "O corpo é, em um primeiro momento, o objeto e a vítima preferencial da civilização, cuja história pode ser lida nos anais do crescente processo de controle daquele, e pelo desenvolvimento das técnicas que medeiam esse domínio."

9 Joana, 29 anos, é engenheira civil. Praticava bodybuilding havia dois anos e participara de três campeonatos de fisiculturismo em Brasília na categoria BodyFitness.
} 
O peso dos discursos científicos faz com que, não raro, "o nome do alimento seja apagado ou secundarizado em função do seu potencial nutriente" (JAEGER, 2009, p. 154), algo que ocorre de modo semelhante com o vocabulário da revista Boa Forma, e que, de modo geral, trata da alimentação em termos de fórmulas e calorias (ALBINO; HAMMES; VAZ, 2011). No caso desse grupo de participantes, os alimentos permitidos para o consumo que mais apareceram são: as "proteínas magras" (peixes, mas principalmente frango) e os de "baixo índice glicêmico" (verduras e saladas). Os carboidratos, ingeridos na forma dos integrais, costumam ser incluídos na dieta quando se está em período de aumento do volume muscular. Nos períodos que precedem às competições - os chamados pre-contest-, dizem elas, os carboidratos são praticamente excluídos. Os alimentos gordurosos seriam evitados, ou ainda, dignos de repulsa. Tanto as proteínas quanto os carboidratos deveriam ser cozidos sem qualquer tempero ou adição de sódio, uma vez que a ingestão desse elemento químico contribuiria para a retenção de líquido, podendo comprometer a aparência "definida" da musculatura. Esses dados indicam que o sabor e a dimensão tradicional da comida parecem sucumbir em nome da necessária reposição dos nutrientes.

Esse processo de racionalização da dieta, tal como apresentado, está atrelado também ao consumo frequente de suplementos alimentares ${ }^{10}$. Eles foram apresentados como item compulsório para a construção do corpo por todas as entrevistadas. Seu uso é frequente em atletas de elite em várias modalidades esportivas. No universo esportivo, a suplementação é tida como aspecto indispensável para o aumento da performance. No entanto, é comum o uso também entre frequentadores de academia e, claro, praticantes de bodybuilding que objetivam alcançar certa performance estética do corpo. Tais produtos são geralmente produzidos na forma de pó ou cápsulas, o que os aproxima de um aspecto de "alimentos-remédios" (SABINO, 2004, p. 233). A suplementação nos leva a questionar se o uso de anabolizantes também faz parte da rotina desse grupo de colaboradoras, uma vez que, conforme descreve Sabino, Luz e Carvalho (2010), no caso dos bodybuilders homens, esse elemento é parte importante do sistema alimentar. Apenas uma das entrevistadas afirmou ter feito uso desses produtos $^{11}$. No entanto, para investigar esse aspecto em específico acreditamos que seriam necessários outros instrumentos de pesquisa, uma vez que aparentemente esse não parece ser um assunto sobre o qual se fala abertamente. Chamamos atenção para esses aspectos acerca da dieta das entrevistadas, sobretudo porque eles envolvem também uma certa subversão dos rituais tradicionais vinculados às práticas alimentares. $O$ ato de alimentarse, se pensado como um gesto que envolve costumes, crenças e nível econômico de uma dada cultura, apresenta uma forte dimensão simbólica. Não que houvesse anulação desses fatores no caso das entrevistadas, mas, ao que parece para elas, alimentar-se significa manter as estruturas físicas do corpo. Isso apresenta, inclusive, consequências no âmbito social da vida de algumas delas. A sociabilidade parece se formar, também, pela identidade entre aqueles que cultivam os mesmos hábitos corporais - e, portanto, exclui aqueles que não os desenvolvem:

Quando tem um grupinho de pessoas, geralmente, sai para comer alguma coisa: é restaurante, cinema, pipoca, sorvete. Eu não posso [comer] essas coisas porque eu faço fisiculturismo, então fica meio complicado para eu ter

10 Segundo Carvalho e Orsano (2007), os suplementos podem ser definidos como produtos feitos à base de vitaminas, minerais, ervas, extratos de tecidos, proteínas e aminoácidos.

11 Joana disse ter feito uso de anabolizantes no primeiro ano de treinamento. Ao responder essa questão Joana baixou um pouco o tom de voz, demonstrando certo melindre. Afirmou que os usos desses produtos atrapalharam mais do que ajudaram, pois contribuíram para que ela ganhasse um pouco de peso. 
esse convívio junto. [...] Quando eu tenho algum encontro, às vezes, é vinte minutos, logo eu tenho que ir embora, beber água, comer, essas coisas (Camila, 38 anos $)^{12}$.

Outro aspecto que é importante destacar, no que diz respeito à dieta, é que elas admitiam não ser fácil manter-se "na linha". Há uma necessidade extrema em exercitar um autocontrole sobre as tentações que a comida pode suscitar:

É muito difícil [seguir o plano alimentar], a falta do carboidrato, né!? É o que dá energia. Então, assim, você olha para um doce, o olho brilha, você olha para qualquer coisa que você nem gosta, você quer comer, porque você sente falta (Ângela, 28 anos) ${ }^{13}$.

Porém, se esse autocontrole sobre a comida se faz necessário, ele parece correr no limite, de maneira que, não raro, aconteceriam os momentos de rendição às sensações do paladar. É o que podemos ver no relato de Fernanda:

Chega um ponto que você desespera e fala 'não aguento mais, eu preciso de um chocolate', 'não aguento mais comer frango'. Chega uma hora que seu corpo está em estado de necessidade. [...] Tem dias que eu falo; 'meu Deus do céu, não consigo me segurar'. Dá tipo uma compulsão. [...] Eu furo às vezes mesmo não podendo, mas por estado de não conseguir segurar mais. Tipo: 'eu estou no meu limite' (Fernanda, 21 anos).

Se, como antes dito, as praticantes parecem de alguma maneira tentar resistir aos rituais que envolvem a alimentação para não comprometerem seus objetivos estéticos, em contrapartida, justamente por não conseguirem permanecer nesse estado por um período prolongado, acabam criando seus próprios "rituais de inversão" (SABINO, 2004, p. 95), momentos em que lhes seria permitido o consumo de alimentos interditados em suas dietas. O melhor exemplo disso é o chamado "dia do lixão", mencionado por algumas entrevistadas. Trata-se de um dia - em um período de uma ou duas semanas - que está liberado o consumo desses alimentos até então não permitidos. No caso das fisiculturistas, este dia costumava ser adiado para ocasiões imediatamente após os campeonatos. ${ }^{14}$ Nem mesmo os rituais de inversão podem ser considerados de fato uma expressão da "perda do controle". A demarcação prévia de seus momentos revela o próprio excesso da regulação sobre si. Um caso particular, que se contrapõe à dinâmica acima, parece ter sido o de Luana. Praticante de musculação havia dezoito anos e competidora há dez, Luana atribuía sua boa performance e sua longevidade na modalidade ao fato de seguir o plano alimentar de modo que ele não se configurava mais como um problema ou uma grande dificuldade para ela.

Embora possamos considerar que a opção pelos hábitos alimentares peculiares das praticantes poderia se configurar por si só como um parâmetro de distinção social, uma vez que há, entre outros aspectos, um alto custo financeiro para mantê-los, talvez devêssemos observar que no caso desse grupo haveria ainda outro elemento de distinção, para além apenas daquele demarcado pelo econômico. Mais do que uma distinção social, no caso das participantes,

12 Camila, 38 anos, morava em Mato Grosso do Sul. Era a homenageada no V Campeonato Brasiliense de Fisiculturismo. Camila era personal trainer e competia na categoria Culturismo. Dizia que sua maior aspiração era participar do mais importante campeonato da modalidade, o Mister Olympia.

13 Ângela, 28 anos, graduara-se em Educação Física, e trabalhava como tatuadora, maquiadora e modelo. Iniciara no esporte em 2010 na categoria Miss Bikini. Embora no campeonato anterior (agosto de 2012) houvesse participado na categoria Bodyfitness, ficando em segundo lugar, pretendia "subir de categoria" ano seguinte e competir na categoria Culturismo.

14 Ao final do V Campeonato Brasiliense de Fisiculturismo, algumas competidoras que por mim foram entrevistadas postaram fotos e comentários em seus perfis na rede social Facebook a respeito das "orgias" alimentares pós campeonato. Um desses comentários chamou a atenção: "Em coma de tanto comer!" 
treino e dietética compõem um engajamento ascético que deve resultar na boa aparência e só. Quando questionadas sobre os motivos que levaram a se engajar nessa prática, as respostas valorizavam, por um lado, a beleza dos corpos e, por outro, o gosto pelos exercícios. Em contraposição às asceses clássicas greco-romanas e cristãs, conforme nos diz Ortega (2003, p.62), cujo objetivo era "a superação e transcendência como prova de habilitação para a vida pública", essas práticas contemporâneas são ressignificadas e tornam-se o fim em si mesmas.

\section{FISICULTURISTAS VERSUS VETERANA}

Embora tenhamos visto algumas semelhanças entre as entrevistadas fisiculturistas (atletas competidoras) e a veterana (amadora) na maneira com que tratam e gerenciam seus corpos, ao analisarmos os resultados com um pouco mais de detalhe, observamos algumas diferenciações importantes, principalmente no que diz respeito ao sentido que atribuem ao bodybuilding, como veremos adiante. Primeiramente, poder-se-ia entender que a diferença entre elas estaria unicamente no volume da musculatura: em que fisiculturistas seriam visivelmente "maiores" que a veterana. Recentemente, as competições de fisiculturismo tanto no exterior quanto aqui no Brasil incluíram em seus regulamentos categorias que prezam por uma estética corporal na qual se prioriza menos o volume muscular que a evidência da musculatura ${ }^{15}$. Um bom exemplo é a categoria Miss Bikini, na qual a beleza e o "físico rasgado"16 são priorizados em detrimento do volume muscular.

0 primeiro desses aspectos diferenciadores diz respeito à maneira com que ambos os tipos compreendem o espaço da academia. A academia de musculação, para a veterana Fernanda, aparece como um local onde o encontro com outras pessoas que partilham dos mesmos hábitos e objetivos parece ter sido um dos grandes motivos que fez com que passasse a dedicar-se ainda mais às mudanças em seu corpo. Trata-se, portanto, de um espaço destinado ao exercício de suas relações de sociabilidade, além de se constituir como local onde encontra certa satisfação, decorrente talvez de um sentimento de pertencimento ou de ter descoberto sua "tribo". Essa maneira de viver e sentir a academia, como espaço de identificação com outras pessoas que possuem "os mesmos objetivos", e segundo a interpretação de Maffesoli (1998), poderia ser vinculada a certo "tribalismo": a constituição de uma nova forma de "socialidade". As relações de socialidade atuais, diz ele, parecem diferir substancialmente das que por muito tempo marcaram a modernidade. Em tempos de relativo silêncio das instâncias que ditavam a vida naquela época (como, por exemplo, a igreja e o trabalho), o contato com outros e a restauração de interesses pertencentes ao domínio da vida cotidiana parecem ter se tornado veículos condutores das novas comunidades e agregações. A investidura sobre a aparência e sobre o corpo, como aspecto integrante daqueles interesses, operaria, na interpretação desse autor, como uma também importante "força relacional" (MAFFESOLI, 1996, p. 151), cujos interesses esgotam-se ali, no que seria a própria relação com os outros. Fernanda, ao falar do encontro com seus "semelhantes", parece trazer para o plano da socialidade aquilo que seria a marca de sua identidade pessoal: as transformações do corpo.

Fernanda diz que sua opção por aderir ao treinamento intenso de musculação deu-se na medida em que seu "gosto" pelo modelo de corpo foi mudando. Disse que antes queria ser

15 Segundo Jaeger e Goellner (2011), quando os músculos exagerados das competidoras deixaram de render lucros às entidades que gestam o esporte, como a International Federation of Bodybuilding (IFBB), novas regras foram formuladas, fazendo com que fossem criadas categorias que limitassem o volume muscular feminino. 
magra, depois se interessou por desenvolver apenas os músculos das pernas e glúteo e por último, se interessou por ter todo o corpo modelado.

Mas somente modificar o corpo não basta. Outros elementos, como as roupas e adereços em voga, entram em cena e são convidados a constituir sua aparência. Se seguirmos ainda a interpretação de Maffesoli (1996), não se trata de sucumbir a tais "modelos". Tratarse-ia na verdade de estabelecer uma identificação com eles, ou seja, com a forma corporal e com a aparência que se imagina. Uma identificação que desembocaria mais uma vez no estreitamento do laço com os que compartilham desse mesmo imaginário, que, no caso de Fernanda, são seus companheiros de academia.

Por outro lado, quando tratamos especificamente das fisiculturistas participantes (competidoras), no que diz respeito à academia, outras características parecem estar em jogo. As questões relativas à socialidade perdem espaço em função da construção de certa "competência esportiva" (WACQUANT, 2002, p. 32). O momento da musculação se aproxima em grande medida do que seria uma prática solitária e efetivamente individualista. A musculação parece adquirir status de treinamento quase "profissional", como de outra modalidade esportiva de alto nível em que concentração e seriedade são essenciais para o bom desempenho. Embora Marcela tenha apontado alguns benefícios relativos à estrutura da academia em que treina, como a qualidade dos aparelhos e a proximidade de sua residência, diferentemente de Fernanda, ela não parece ver esse ambiente como um espaço destinado ao fortalecimento de suas relações sociais. Ao contrário, enfatiza que a desvantagem daquele lugar está nesse caráter relacional do espaço. Por isso, Marcela diz que sempre procura frequentar a academia nos momentos em que há pouco fluxo de pessoas. Só assim, diz ela, não há interrupções, nem comprometimento do treinamento.

Outra característica que percebemos conformar certa identidade ao tipo fisiculturista seria o cuidado na exposição do próprio corpo, o qual parece se aproximar do que Wacquant (2002, p.74) vai chamar, em seu estudo sobre boxeadores, de "regra implícita" que algumas fisiculturistas compartilham. No relato de Luana podemos claramente notar essa preocupação com a exposição dos corpos das atletas:

Eu vejo muitas pessoas utilizando de maneira ruim o esporte. Para falar a verdade, a maioria das pessoas, as meninas e os meninos. Porque como é um esporte que apresenta muito o corpo e o objetivo é aquela perfeição, tem muita gente que utiliza isso de maneira ruim, utilizando em fotos, até usando o lado erótico na coisa toda. [...] Eu vejo várias competidoras em sites, fazendo webcam, fazendo fotos e vídeos, devido ao corpo para ter dinheiro (Luana, 44 anos) ${ }^{17}$.

A exposição erótica dos corpos musculosos foi, inclusive, objeto de estudo na Inglaterra. Richardson (2008) investigou a crescente forma de representação dos corpos de praticantes de bodybuilding, tanto de homens, quanto de mulheres, nos chamados workship: sites e vídeos em que bodybuilders se exibem no que o autor denomina de "strange erotic spetacle" (RICHARDSON, 2008, p. 290). Embora fosse necessário investigar de maneira mais profunda a dimensão desse tipo de exibicionismo aqui no Brasil, não é difícil encontrar sites em que atletas/modelos exibem os músculos frequentemente com pouca roupa ${ }^{18}$.

17 Luana, 44 anos, advogada, era presidente da Federação Brasiliense de Fisiculturismo. Competira por dez anos na modalidade, consagrouse tetracampeã brasileira na categoria Culturismo e bicampeã sul-americana na categoria de duplas. Luana afirmava ser da "fase antiga" do fisiculturismo. 
O exibicionismo dos corpos, para além dos palcos de competições de fisiculturismo, não é, entretanto, algo recente. Segundo Jaeger (2009), Eugene Sandow - considerado um dos precursores do bodybuilding - teria percebido que sua forma poderia ser um meio importante não só para a promoção das competições de bodybuilding que organizava, como também para sua autopromoção ${ }^{19} \mathrm{e}$ ampliação de seus negócios no início do século XX. Os corpos femininos musculosos começaram a ser fotografados mais tardiamente, somente no final do século XX e início do XXI. A circulação de suas imagens por um tempo esteve ligada estritamente à modalidade esportiva do fisiculturismo, por meio de revistas esportivas da época.

Embora a preservação da imagem do corpo presente tanto no discurso de Luana como também no de Marcela ${ }^{20}$ seja uma tentativa de demarcação do que seria uma identidade de atleta dessa modalidade, essa parece ser uma característica que não é predominante entre as atletas e que tem lá suas contradições. Se pensarmos que a musculação competitiva vem ganhando cada vez mais adeptos nos últimos anos ${ }^{21}$, poderíamos atribuir esse aumento de demanda a uma maior visibilidade que os corpos vêm ganhando fora dos palcos de competições.

Atualmente, vemos com certa frequência corpos de mulheres musculosas em exposição nos programas de TV, festividades carnavalescas, concursos de beleza etc. Uma das depoentes dessa pesquisa, Ângela, pode em parte ilustrar essa situação. Ângela se divide entre as competições de fisiculturismo e concursos de beleza, trabalhos como modelo fotográfica, além de ter participado recentemente de um programa de televisão de reality show. Em seu perfil da rede na rede social Facebook, álbuns de fotos de sua performance em competições de fisiculturismo se misturam às de outros trabalhos que fez, como os mencionados acima. Parece que a possibilidade de captar e estampar publicamente imagens potencializa a ascensão de um modelo de corpo hiperbólico.

Outro aspecto que julgamos interessante ser citado diz respeito à atuação profissional de três atletas em particular: Marcela, Ângela e Camila, que, com formação superior completa ou em andamento em Educação Física, apontam benefícios da prática que ecoam em seus campos de trabalho. Já formadas, Ângela e Camila afirmam que, desde que começaram a participar de competições, o número de alunos de personal trainer que atendem aumentou significativamente. Marcela, que na época da entrevista estava em vias de terminar sua graduação, também já projetava essa possibilidade de ascensão profissional que a prática da musculação competitiva poderia lhe proporcionar.

O personal trainer, ou como Malysse (2002, p. 99) coloca, "o mentor da corpolatria", é um dos especialistas legalmente qualificados - e certamente, o que goza de maior prestígio social - para dar orientações no campo da musculação. O que podemos notar aqui é que mesmo a construção do que seria uma identidade profissional parece acontecer no plano da aparência, ou, por outro, pela incorporação daquela. A competência profissional parece ser vista e comparada à competência esportiva. O que está em jogo, de forma mais decisiva, é a

\footnotetext{
19 Segundo a autora, a imagem de seu corpo chegou a estampar embalagens de chocolate e cigarros, além de ter ilustrado livros e revistas de treinamento muscular da época.

20 Marcela se manifestou em seu perfil da rede social Facebook quando uma de suas amigas - também fisiculturista - falou com tom de indignação sobre os convites que vem recebendo de fotógrafos para "posar com pouca roupa segurando anilhas". Marcela e sua amiga dizem que o reconhecimento que objetivam ter é pela "dedicação" e "disciplina" ao esporte.

21 Aqui falamos do esporte em Brasília. O teatro nacional da cidade foi insuficiente para o número de espectadores no último campeonato de fisiculturismo (agosto de 2012). Segundo informações de Luana, presidente da Federação Brasiliense de Fisiculturismo, a cada edição aumenta também o número de atletas em todas as categorias.
} 
aptidão em fazer de seu corpo um modelo estético a ser alcançado. A respeito disso, Ângela menciona que "se eu consigo fazer comigo, porque não conseguirei fazer com os outros"?

Se pudéssemos tecer argumentos que promovessem certa unidade aos diferentes sentidos atribuídos ao corpo musculoso entre as entrevistadas, eles estariam relacionados à "eficácia da aparência" (MAFFESOLI, 1996, p.168). Se por muito tempo a composição da aparência esteve ligada ao que já fora considerado frívolo ou superficial - mas que ainda assim nunca chegou a ser abandonada por completo -, como podemos ver atualmente, ela tem sido um importante - e porque não o mais importante? - descritor de si.

\section{UMA NOTA FINAL}

Dedicamo-nos neste estudo a investigar a relação entre modificação corporal e construção identitária de mulheres praticantes de bodybuilding. Optamos por explorar outros aspectos dos resultados para além das questões relativas à subversão da normatividade dos modos de ser femininos. A nosso ver, as discussões acerca da transgressão e dos desvios daquilo considerado normativo, que, vale destacar, passou a ser compreendido como nova forma de vida (ORTEGA, 2012), encontram no corpo o seu denominador comum. Em outras palavras, a opção dessas mulheres por transgredir o modelo de corpo socialmente entendido como aquele que representa o feminino não tarda em reincidir na mesma dinâmica de outros sujeitos em que a constituição de si se desloca para o externo, para a aparência.

É por isso que as questões discutidas acerca do autocontrole, da disciplina, do treinamento e da alimentação restritiva ganham lugar de destaque nesse processo, bem como o próprio sentido que as praticantes de bodybuilding atribuem à imagem do corpo que conseguem construir, seja para comprovar um etos esportivo, para contribuir para a ascensão profissional, seja para fins de socialização.

\section{REFERÊNCIAS}

ALBINO, Beatriz Staimbach; HAMMES, Priscila Daniela; VAZ, Alexandre Fernandez. Sobre o bemestar na revista Boa Forma: corpo, lazer, normalização. Educação e Realidade, v. 36, n.2, p. 569$585,2011$.

ARAÚJO, Amanda Mello Andrade. Entre músculos e feminilidades: construção identitária de mulheres praticantes de bodybuilding. 2013. 54f. Trabalho de Conclusão de Curso (Licenciatura em Educação Física) - Centro de Desportos, Universidade Federal de Santa Catarina, Florianópolis, 2013.

CARVALHO, Conceição de Maria Aguiar; ORSANO, Francisco Evaldo. Perfil dos consumidores de suplementos alimentares praticantes de musculação em academias de Teresina. In: ENCONTRO DE PESQUISA EM EDUCAÇÃO FÍSICA E ÁREAS AFINS, 3, 2007, Teresina. Anais...Teresina: UFPI, 2007. Disponível em <http://leg.ufpi.br/subsiteFiles/def/arquivos/files/PERFIL\%20DOS\%20 CONSUMIDORES\%20DE\%20SUPLEMENTOS\%20ALIMENTARES\%20PRATICANTES\%20DE\%20 MUSCULAO\%20EM\%20ACADEMIAS\%20DE\%20TERE.pdf>. Acesso em: 12 fev. 2016.

COSTA, Jurandir Freire. 0 vestígio e a aura: corpo e consumismo na moral do espetáculo. Rio de Janeiro: Garamond, 2004. 
HANSEN, Roger; VAZ, Alexandre Fernandez. Treino, culto e embelezamento do corpo: um estudo em academias de ginástica e musculação. Revista Brasileira de Ciências do Esporte, v. 26, n.1, p 135152, set. 2004

JAEGER, Angelita Alice. Mulheres atletas da potencialização muscular e a construção de arquiteturas corporais no fisiculturismo. 2009. 240f. Tese (Doutorado) - Escola de Educação Física, UFRGS, Porto Alegre, 2009.

JAEGER, Angelita Alice; GOELLNER, Silvana Vilodre. O músculo estraga a mulher? A produção de feminilidades no fisiculturismo. Revista Estudos Feministas, v. 3, n. 19, p. 955-975, dez. 2011.

MAFFESOLI, Michel. No fundo das aparências. Petrópolis: Vozes, 1996.

MAFFESOLI, Michel. 0 Tempo das Tribos: 0 declínio do individualismo nas sociedades de massa. Rio de Janeiro: Forense Universitária, 1998.

MALYSSE, Stéphane. Em busca dos (H)alteres-ego: Olhares franceses nos bastidores da corpolatria carioca. In: GOLDENBERG, M. (Org.) Nu e Vestido: dez antropólogos revelam a cultura do corpo carioca. Rio de Janeiro: Record, 2002. p. 79-138.

ORTEGA, Francisco. Práticas de ascese corporal e constituição de bioidentidades. Caderno de saúde coletiva, v. 11, n. 1, p. 59-77, jan./jun. 2003.

ORTEGA, Francisco. 0 corpo incerto. Rio de Janeiro: Garamond, 2012.

RICHARDSON, Niall. Flex-rated! Female bodybuilding: feminist resistance or erotic spectacle? Journal of Gender Studies, v.17, n.4, p.289-301, Dec. 2008.

SABINO, César. 0 peso da forma: cotidiano e uso de drogas entre fisiculturistas. 2004. 342f. Tese (Doutorado em Sociologia e Antropologia) - Instituto de Filosofia e Ciências Sociais, UFRJ, Rio de Janeiro, 2004.

SABINO, César. Musculação: expansão e manutenção da masculinidade. In: GOLDENBERG, Mirian (Org.). Os novos desejos. Rio de Janeiro: Record, 2000. p.61-103.

SABINO, César; LUZ, Madel Therezinha. Forma da dor e dor da forma: significado e função da dor física entre praticantes de bodybuilding em academia de musculação do Rio de Janeiro. Physis

Revista de Saúde Coletiva, v.24, n.2, p. 467-490, 2014.

SABINO, César; LUZ, Madel Therezinha; CARVALHO, Maria Cláudia. O fim da comida: suplementação alimentar e alimentação entre frequentadores assíduos de academias de musculação e fitness do Rio de Janeiro. História, Ciência, Saúde-Manguinhos, v.17, n.2, p. 343-356, 2010.

SANT'ANNA, Denise Bernuzzi. As infinitas descobertas do corpo. Cadernos Pagu, v. 14, p. 235-249, 2000.

VAZ, Alexandre Fernandez. Treinar o corpo, dominar a natureza: notas para uma análise do esporte com base no treinamento corporal. Caderno CEDES, v.19, n. 48, p. 89-108, ago. 1999.

WACQUANT, Loïc. Corpo e alma: notas etnográficas de um aprendiz de boxe. Rio de Janeiro: Relume Dumará, 2002.

\section{Apoio:}

CNPq; bolsa IC, bolsa mestrado, apoio à pesquisa, bolsa PQ. 